\title{
Is Momentum Due to Data-Snooping?
}

\author{
Johan Ericsson * \\ Andrés González \\ Stockholm School of Economics \\ Stockholm School of Economics \\ Banco de la República de Colombia \\ Stockholm School of Economics \\ SSE/EFI Working Paper Series in Economics and Finance \\ No.536
}

September 2003

\begin{abstract}
This paper explores the profitability of portfolio-based momentum strategies. The data consists of all NYSE, AMEX, and NASDAQ stocks on the CRSP database. The analysis considers the period July 1963 to December 2002 and the tests are performed on portfolios formed on industry, size and book-to-market. The departure from earlier studies lies in the way we test for profitability. To avoid the serious problem of data-snooping we apply the procedure provided by White (2000). Overall, we find strong evidence of a momentum effect where an investor takes a long position on the winner portfolio and a short position on the loser portfolio. Hence, we reject the hypothesis of weak market efficiency. Splitting the sample in two parts, 1963:07 to 1981:12 and 1982:01 to 2002:12 we found that the best momentum strategy was profitable during the first period and not during the second. The overall significance is thus driven by events in the earlier part of the sample and it appears that the market has become more efficient.

Keywords: Momentum effect; Reality Check; Data-snooping.

JEL codes: G11, G12, G14.
\end{abstract}

Acknowledgement: We would like to thank Sune Karlsson and the seminar participants at the Department of Finance at the Stockholm School of Economics and at the Workshop in Econometrics and Computational Economics in Helsinki 2003 for their valuable comments and suggestions. Additionally, we would like to thank Peter Schotman for proposing the idea for the paper.

Stockholm School of Economics, P.O. Box 6501, SE-113 83 Stockholm, Sweden

*stjer@hhs.se 


\section{Introduction}

In efficient markets, asset prices are assumed to fully reflect all available information in the market. Consequently, it should be impossible to earn risk adjusted abnormal returns by exploiting investment strategies based on past information. However, several empirical studies suggest that past return are powerful predictors of future stock returns. It appears that if you buy a portfolio of stocks that performed best in the last year, and short a portfolio of the worst performers, you will make money over a period of six months and perhaps a year. This effect is known as the "momentum".

Several studies have uncovered the momentum anomaly in the U.S. stock market. Jegadeesh and Titman (1993) show that strategies that buy stocks that have performed well and sell stocks that have performed poorly over a horizon of three to twelve months generate significant positive returns over the same horizon. They state that one explanation could be that investors who follow a momentum strategy temporarily move prices away from their long run values. Conrad and Kaul (1998) finds similar results as Jegadeesh and Titman (1993). Chan, Jegadeesh, and Lakonishok (1996) find that price momentum and earnings momentum each predict large drifts in future stock returns. Their explanation is that the market responds gradually to new information. These papers are all based on US stocks. Similar evidence in favour of the momentum effect has been documented for Europe market by Rouwenhorst (1998) who shows that abnormal returns to momentum strategies could be found on 12 European markets. Evidence on momentum has been found for emerging markets by Rouwenhorst (1999) and van der Hart, Slagter, and van Dijk (2001). While the momentum effect has been well documented, the cause of momentum is still an open issue. Fama and French (1996) argue that many of the anomalies in asset returns are related, and that their three-factor model captures these anomalies.

Recently, several authors have tried to connect momentum to other factors than firm specific. Moskowitz and Grinblatt (1999) ague that momentum can be traced to industry factors and Lewellen (2002) extend the analysis to size and book-to-market sorted portfolios.

An important issue when evaluating a large set of trading rules is data-snooping. As argued by Lo and MacKinlay (1990), the data-snooping bias can be substantial in financial studies. Data snooping occurs when a given set of data is used more than once for inference or model selection. The problem of data-snooping has been mentioned in several papers. For example, Merton (1987, p. 107) poses the question "Is it reasonable to use the standard t-statistic as a valid measure of significance when the test is conducted on the same data used by many earlier studies whose result influenced the choice of theory to be tested?" Savin (1984) and Lakonishok and Smidt (1984) made the remark that the actual size of a t-test that follows a search for the largest possible t-statistics can be very different from its nominal size. To address the question of data mining in momentum strate- 
gies Jegadeesh and Titman (2001) test for momentum using an extended data set. They find that momentum strategies continue to be profitable at about the same magnitude as in the earlier period.

This paper explores the profitability of portfolio-based momentum strategies. More specifically, we investigate if momentum exists in a set of portfolios formed on industry, size and book-to-market. The departure from earlier studies lies in the way we test for profitability. To deal with the problem of data snooping we use the procedure provided by White (2000). Hence, we investigate if a momentum strategy is superior over a benchmark model once the effects of data-snooping have been accounted for. This procedure is known as White's Reality Check.

\section{$2 \quad$ Data and descriptive statistics}

The data consists of all NYSE, AMEX, and NASDAQ stocks on the CRSP database. The analysis considers the period July 1963 to December 2002. Furthermore, the tests are performed on portfolios formed on industry, size, and book-to-market. The industry portfolios are constructed by assigning each stock to an industry portfolio at the end of June of year $t$ based on its four digit SIC code at that time. The size and book-to-market portfolios are constructed at the end of June of year $t$ using NYSE breakpoints respectively. All portfolios are value-weighted ${ }^{1}$.

Table 1 reports summary statistics for 17 industry portfolios, 10 size and 10 book-to-market portfolios and the 25 size and book-to-market portfolios. The average returns for the industry portfolios range from $0.69 \%$ to $1.15 \%$ resulting in a annualized spread of $5.56 \%$. The large number of firms in the industries indicates that the industry portfolios are well diversified. An F-test of whether the mean returns differs across industries is not rejected, suggesting there is little cross-sectional variation in the industry sample means. The average returns for the book-to-market and size portfolios range from $0.81 \%$ to $1.30 \%$ and $0.87 \%$ to $1.18 \%$, which result in annualized spreads of $5.92 \%$ and $3.78 \%$, respectively. Furthermore, the large average number of firms indicates that the portfolios are well diversified. Again, F-tests are not rejected.

The cross sectional variation is larger in the size and book-to-market portfolios. The annualized spread is $11.28 \%$ and the number of firms in each portfolio is lower. However, the F-test of equal mean returns is not rejected. Overall, firm specific factors should not be important in these portfolios.

\section{Momentum Portfolios}

To form the momentum strategies we have to specify the length of the period over which we rank the returns $k$, the proportion of winner and losers to include $q$, and

\footnotetext{
${ }^{1}$ We thank Kenneth R. French for providing the data at http://mba.tuck.dartmouth.edu/pages/ faculty/ken.french/data_library.html.
} 
Table 1a: Descriptive statistics

\begin{tabular}{lccc}
\hline \hline \multicolumn{3}{c}{ Industry } & \\
\hline Portfolio & Average Return & Std.dev & Ave. No. of firms \\
\hline Food & 1.135 & 4.531 & 151 \\
Mining and Minerals & 0.884 & 6.362 & 68 \\
Oil & 1.034 & 5.246 & 198 \\
Textiles & 0.955 & 6.119 & 135 \\
Consumer Durables & 1.028 & 5.757 & 159 \\
Chemicals & 0.887 & 5.308 & 80 \\
Drugs, Soap, Tobacco & 1.153 & 4.817 & 164 \\
Construction & 0.973 & 5.869 & 197 \\
Steel & 0.699 & 6.369 & 82 \\
Fabricated Products & 0.898 & 5.423 & 57 \\
Machinery Equipment & 0.946 & 6.534 & 591 \\
Automobiles & 0.871 & 6.031 & 70 \\
Transportation & 0.991 & 5.902 & 152 \\
Utilities & 0.773 & 4.131 & 166 \\
Retail Stores & 1.062 & 5.601 & 286 \\
Finance & 1.045 & 5.108 & 783 \\
Other & 0.866 & 5.034 & 1275 \\
\hline \hline
\end{tabular}

\begin{tabular}{lccc}
\hline \multicolumn{4}{c}{ Book-to-Market } \\
\hline Portfolio & Average return & Std.dev & Ave. No. of firms \\
\hline Low & 0.8152 & 5.3385 & 638 \\
2 & 0.9340 & 4.8461 & 389 \\
3 & 0.9458 & 4.8024 & 352 \\
4 & 0.9305 & 4.7247 & 324 \\
5 & 0.9552 & 4.4304 & 319 \\
6 & 1.0728 & 4.4267 & 321 \\
7 & 1.1496 & 4.3656 & 326 \\
8 & 1.190 & 4.3586 & 336 \\
9 & 1.2441 & 4.6578 & 368 \\
High & 1.2996 & 5.4573 & 457 \\
\hline \hline
\end{tabular}

\begin{tabular}{lccc}
\hline \multicolumn{4}{c}{ Size } \\
\hline Portfolio & Average return & Std.dev & Ave. No. of firms \\
\hline Small & 1.1802 & 6.4667 & 2287 \\
2 & 1.1310 & 6.3371 & 568 \\
3 & 1.1529 & 6.0494 & 374 \\
4 & 1.1161 & 5.8716 & 288 \\
5 & 1.1466 & 5.5599 & 242 \\
6 & 1.0408 & 5.3194 & 204 \\
7 & 1.0690 & 5.1775 & 182 \\
8 & 1.0418 & 5.0764 & 170 \\
9 & 0.9728 & 4.6413 & 156 \\
Large & 0.8675 & 4.3398 & 150 \\
\hline \hline
\end{tabular}


Table 1b: Descriptive statistics

\begin{tabular}{lcccc}
\hline \hline \multicolumn{5}{c}{ 25 Size-book-to-market } \\
\hline Size & B/M & Average Return & Std.dev & Ave. No. of firms \\
\hline Small & Low & 0.632 & 8.276 & 531 \\
& 2 & 1.200 & 7.087 & 332 \\
& 3 & 1.280 & 6.110 & 329 \\
& 4 & 1.491 & 5.675 & 393 \\
& High & 1.566 & 5.944 & 637 \\
\hline 2 & Low & 0.801 & 7.561 & 164 \\
& 2 & 1.063 & 6.114 & 115 \\
& 3 & 1.326 & 5.405 & 113 \\
& 4 & 1.389 & 5.173 & 103 \\
& 5 & 1.422 & 5.759 & 80 \\
3 & 1 & 0.830 & 6.904 & 122 \\
& 2 & 1.143 & 5.503 & 88 \\
& 3 & 1.155 & 4.974 & 80 \\
& 4 & 1.288 & 4.724 & 67 \\
& High & 1.433 & 5.377 & 47 \\
\hline 4 & Low & 0.955 & 6.158 & 100 \\
& 2 & 0.931 & 5.196 & 74 \\
& 3 & 1.131 & 4.892 & 64 \\
& 4 & 1.255 & 4.681 & 53 \\
& High & 1.346 & 5.414 & 35 \\
\hline Large & Low & 0.883 & 4.877 & 107 \\
& 2 & 0.911 & 4.599 & 66 \\
& 3 & 0.951 & 4.375 & 53 \\
& 4 & 1.056 & 4.308 & 43 \\
& High & 1.019 & 4.799 & 25 \\
\hline \hline
\end{tabular}


the length of the period for holding the selected portfolios $l$. Letting $k=1, \ldots, K$, $l=1, \ldots, L$ and $q=q_{i}, i=1, \ldots, Q$ yields $K Q L$ different strategies.

Let $R_{i t}$ be the net return for portfolio $i$ in period $t$, then the return of each momentum strategy is calculated as follows. Let

1. Calculate the geometrically compounded return for portfolio $i$ as

$$
R_{i t}(k)=\prod_{j=1}^{k}\left(1+R_{i, t-j}\right)-1, \quad t>k .
$$

2. To construct the portfolios of winners and losers we sort the portfolios accordingly to the returns calculated in step 1 . The winner portfolio is then formed by giving equal weights to the $q$ percent portfolios with the highest geometrically compounded return. Similarly, we form the loser portfolio by giving equal weights to the $q$ percent portfolios with the lowest geometrically compounded return. The momentum strategy generate a zero-cost portfolio, that buys the winners and sells the losers. This position is held for the next $l$ months.

3. Every month a new momentum portfolio is formed and the oldest momentum portfolio is retired. After an initial ranking period of length $K+L$ we have $L$ different momentum portfolios. The return of the strategy is the average return from all $L$ portfolios that are held simultaneously during period $t$.

4. Working through the $T$ periods we have a time series of momentum returns for each of the $K L Q$ momentum strategies.

\section{Is momentum due to data-snooping?}

White (2000) presents a methodology for testing hypothesis about predictive superiority over a benchmark model taking into account the effect of data-snooping. To evaluate the profitability of the momentum strategies we compare the returns of each strategy to the return of the benchmark. Since the momentum portfolios are zero-cost portfolios by construction, the appropriate benchmark return is zero.

Let $X$ be the $(T-K-L) \times(K L Q)$ matrix of momentum returns. The vector of average returns is

$$
\bar{X}=\frac{1}{T-K-L} \sum_{t=K+L+1}^{T} X_{t} .
$$

The null hypothesis is that the strategy with the highest average return is no better than the benchmark. Hence, the null hypothesis is

$$
\mathrm{H}_{0}: \max _{j=1, \ldots, K L Q} \mathrm{E}\left(\bar{X}_{j}\right) \leq 0 .
$$


and the alternative hypothesis is that the best strategy is superior to the benchmark.

The null hypothesis can be tested by the following test statistic

$$
V_{\text {max }}=\max _{j=1, \ldots, K L Q} \sqrt{(T-K-L)}\left(\bar{X}_{j}\right) .
$$

Since the asymptotic distribution of $V_{\max }$ under the null hypothesis is nonstandard, White (2000) suggested two ways to approximate it. The first option is Monte Carlo simulation. In this case, one needs to estimate consistently $\Omega$, the covariance matrix of the returns. Then one samples returns from $N(0, \widehat{\Omega})$ and the desired pvalue can be obtained from the distribution of the extremes of $N(0, \widehat{\Omega})$. The second approach is to use the bootstrap to draw from the empirical distribution of $\bar{X}$. In our case the number of strategies exceeds the number of observations so the only feasible implementation is the second one. In addition, drawing from the empirical distribution has the advantage that it does not rely on restrictive distributional assumptions.

The bootstrap samples can be generated in several ways. One approach is the stationary bootstrap of Politis and Romano (1994), another is the block bootstrap of Künsch (1989). The stationary bootstrap is used for two reasons. First, it generates stationary samples and second, it does not requires the determination of an optimal block-length.

Let $\xi_{b}, b=1, \ldots, B$ be $(T-K-L \times 1)$ vectors of row indexes. The stationary bootstrap constructs indexes, $\xi_{b}, b=1, \ldots, B$, by combining blocks with random length. Where the length follows a geometric distribution with parameter $\rho \in$ $[0,1)$. The expected block length is $1 / \rho$.

The bootstrap samples are given by $X_{b, t}^{*}=X_{\xi_{b, t}}, t=1, \ldots,(T-K-L)$, which leads to the sample average $\bar{X}_{b}^{*}, b=1, \ldots, B$. Furthermore, $\bar{X}_{b}^{*}$ preserves the unconditional means, the cross-sectional correlation (by sampling vector of returns) and any time dependence in the average returns (2). The bootstrap sample averages are used to construct the statistic

$$
V_{\max , b}^{*}=\max _{j=1, \ldots, K L Q} \sqrt{(T-K-L)}\left(\bar{X}_{b}^{*}-\bar{X}\right), \quad b=1, \ldots, B
$$

and White's Reality Check p-value is obtained as the fraction of times that $V_{\text {max }}$ is larger then $V_{\max , b}^{*}$ for $b=1, \ldots, B$. By using the maximum values over all $K L Q$ strategies, the Reality Check p-values is corrected for the effect of data-snooping.

\section{$5 \quad$ Empirical Results}

This section evaluates the profitability of momentum investment strategies described in the previous sections.

Table 2 contains the momentum profits for the three different portfolios using 6 and 12 month for formation. Each momentum portfolio consists of the 20 percent 
Table 2: Momentum profits

Panel A: 17 Industry Portfolios

\begin{tabular}{|c|c|c|c|c|c|c|c|c|c|c|c|c|}
\hline & \multicolumn{12}{|c|}{ Month after formation $(\mathrm{L})$} \\
\hline & 1 & 2 & 3 & 4 & 5 & 6 & 7 & 8 & 9 & 10 & 11 & 12 \\
\hline $\mathrm{K}=6$ & 0.27 & 0.27 & 0.27 & 0.33 & 0.41 & 0.46 & 0.47 & 0.46 & 0.44 & 0.41 & 0.37 & 0.32 \\
\hline $\mathrm{K}=12$ & 0.64 & 0.59 & 0.52 & 0.50 & 0.48 & 0.45 & 0.42 & 0.40 & 0.36 & 0.33 & 0.30 & 0.26 \\
\hline \multicolumn{13}{|c|}{ Panel B: Book-to-Market Portfolios } \\
\hline & \multicolumn{12}{|c|}{ Month after formation (L) } \\
\hline & 1 & 2 & 3 & 4 & 5 & 6 & 7 & 8 & 9 & 10 & 11 & 12 \\
\hline $\mathrm{K}=6$ & 0.20 & 0.17 & 0.19 & 0.19 & 0.18 & 0.196 & 0.19 & 0.17 & 0.16 & 0.14 & 0.13 & 0.10 \\
\hline $\mathrm{K}=12$ & 0.33 & 0.27 & 0.23 & 0.20 & 0.17 & 0.14 & 0.12 & 0.10 & 0.09 & 0.08 & 0.08 & 0.07 \\
\hline \multicolumn{13}{|c|}{ Panel C: Size Portfolios } \\
\hline & \multicolumn{12}{|c|}{ Month after formation (L) } \\
\hline & 1 & 2 & 3 & 4 & 5 & 6 & 7 & 8 & 9 & 10 & 11 & 12 \\
\hline $\mathrm{K}=6$ & 0.19 & 0.16 & 0.19 & 0.22 & 0.28 & 0.32 & 0.33 & 0.32 & 0.31 & 0.31 & 0.31 & 0.28 \\
\hline $\mathrm{K}=12$ & 0.52 & 0.47 & 0.46 & 0.45 & 0.48 & 0.48 & 0.48 & 0.47 & 0.45 & 0.44 & 0.43 & 0.42 \\
\hline \multicolumn{13}{|c|}{ Panel D: Size-book/market Portfolios } \\
\hline & \multicolumn{12}{|c|}{ Month after formation (L) } \\
\hline & 1 & 2 & 3 & 4 & 5 & 6 & 7 & 8 & 9 & 10 & 11 & 12 \\
\hline$K=6$ & 0.47 & 0.41 & 0.39 & 0.38 & 0.39 & 0.42 & 0.42 & 0.40 & 0.38 & 0.36 & 0.34 & 0.30 \\
\hline $\mathrm{K}=12$ & 0.64 & 0.56 & 0.51 & 0.47 & 0.45 & 0.42 & 0.40 & 0.38 & 0.35 & 0.32 & 0.30 & 0.27 \\
\hline
\end{tabular}

The table contains the momentum profits in percentage. $K$ and $L$ stands for the ranking and the holding period, respectively. In the industry and size-book/market portfolios the $20 \%$ of winners and losers corresponds to 2 and 3 portfolios, respectively.

with the highest compounded return and the 20 percent lowest compounded returns. For the strategy based on 12-month returns, the profit of the winner minus the loser portfolio is highest in the month immediately following formation. After one month, the profits decline. The profits based on 6-month returns are less regular. The momentum profits are consistent with Moskowitz and Grinblatt (1999) and Lewellen (2002) except that they find the reversal in the industry portfolios for 9 or more month after formation.

Note that we have not investigated if momentum profits differ significantly from the benchmark return. In this paper we want to take into account the problem of data-snooping and therefore use the method proposed by White (2000) known as the White's reality check.

\subsection{Is Momentum Due to Data-Snooping?}

White's reality check is applied to a universe of momentum strategies. For a given proportion of winner and loser portfolios $q$, we let the ranking $k$, and holding period $l$, range from 1 to 12 months. The proportion of winner and loser portfolios is $10 \%$, 
Table 3: Momentum test results

\begin{tabular}{lcc}
\hline \hline & 17 Industry & Book-to-Market \\
\hline Period & White's p-value & White's p-value \\
\hline $196307-200212$ & $0.006(0.001)$ & $0.104(0.021)$ \\
$196307-198112$ & $0.013(0.003)$ & $0.436(0.040)$ \\
$198201-200212$ & $0.145(0.017)$ & $0.130(0.018)$ \\
\hline \hline & Size & Size-book/market \\
\hline Period & White's p-value & White's p-value \\
\hline $196307-200212$ & $0.003(0.001)$ & $0.002(0.001)$ \\
$196307-198112$ & $0.012(0.002)$ & $0.009(0.002)$ \\
$198201-200212$ & $0.095(0.026)$ & $0.061(0.017)$ \\
\hline \hline
\end{tabular}

Nominal p-value in parenthesis. The p-values are based on 1000 bootstrap samples. $\rho=0.2$ which implies an expected blocklength of 5 observations.

20\%, 30\%, and 40\%. This results in 576 momentum portfolios. Since the industry contains 17 portfolios we cannot take exactly 10\%, 20\%, 30\% and 40\% winners and losers. The same problem exists for the 25 size-book/market portfolios. Instead, we take 2, 4, 5 and 7 and 3,5,8 and 10 winner and loser portfolios in industry and size-book/market. We also consider two sub-samples, 1963:07-1981:12 and 1982:01-2002:12.

In Table 3 we report the result for testing the null hypothesis that the best momentum strategy does not outperform the benchmark, which is the zero return. The table reports White's Reality Check p-value and the nominal p-value (in parenthesis). The number of bootstrap samples is 1000 and let $(\rho=0.2)$ which implies an expected block length of 5 observations $^{2}$. The nominal p-value is the result of applying the bootstrap to the best trading rule only. Hence, by using the nominal p-value we ignore the effects of data-snooping and the difference between the two p-values yields the magnitude of data-snooping bias.

Firstly, and perhaps most important, we note that the data-snooping bias is very substantial. Neglecting the data-snooping effect we always reject the null hypothesis while the evidence is mixed when taking account of data-snooping. Starting with the whole sample period, the momentum effect is significant for the industry, size and the double sorted portfolios. For the book-to-market portfolios the White reality check p-values are all above $10 \%$ indicating that momentum is not that strong for the these portfolios.

Considering the sub samples yields different results. Starting with the period 1963:07-1981:12 we obtain very low p-values for the industry, size, and sizebook/market portfolios. During the second period 1982:01-2002:12 we have the

\footnotetext{
${ }^{2}$ In Appendix we investigate the robustness of the results with respect to $\rho$. It appears like our results are insensitive to the choice of $\rho$
} 
opposite. The reality check p-values are $14.5 \%, 9.5 \%$, and $6.1 \%$ for industry, size and size- book/market, respectively. Using the conventional 5.0\% significance level the null of no superior returns in momentum strategies cannot be rejected. This indicates that the profitability of momentum strategies is due to the high profitability over the first half of the sample period.

A similar method to test for superior predictive has been proposed by Hansen (2003). Unlike the White reality check it is not sensitive to poor and irrelevant alternatives. We carry out the same analysis using Hansen's procedure. Since the main conclusions do not change we present the results based on White's reality check only.

\section{Summary and Conclusion}

This paper explores the profitability of portfolio-based momentum strategies. The data consists of all NYSE, AMEX, and NASDAQ stocks on the CRSP database. The analysis considers the period July 1963 to December 2002 and the tests are performed on portfolios formed for industry, size, book-to-market and double sorted on size and book-to-market.

The departure from earlier studies lies in the way we test for profitability. To avoid the serious problem of data-snooping we apply the procedure provided by White (2000). Hence, we investigate if a momentum strategy is superior over a benchmark model once the effects of data-snooping have been accounted for.

Overall, we find strong evidence of a momentum effect where an investor takes a long position on the winner portfolio and a short position on the loser portfolio. Hence, we reject the hypothesis of weak market efficiency. Splitting the sample in two parts, 1963:07 to 1981:12 and 1982:01 to 2002:12 we found that the momentum strategy was profitable during the first period and not during the second. The overall significance is thus driven by events in the earlier part of the sample and it appears that the market has become more efficient.

Finally, and perhaps most important, our results shows that data snooping bias can be very substantial. In this study, neglecting the problem would lead to very different conclusions. 


\section{References}

Chan, K. C., N. Jegadeesh, and J. Lakonishok (1996): "Momentum strategies," Journal of Finance, 51, 1681-1713.

Conrad, J., and G. Kaul (1998): "An Anatomy of Trading Strategies," Review of Financial Studies, 11, 489-519.

FAma, E., And K. R. French (1996): "Multifactor explanations of asset pricing anomalies," Journal of Finance, 51, 55-84.

Hansen, P. R. (2003): "A test for superior predictive ability," Brown University, Department of Economics, Working Paper Series, 2003-09.

Jegadeesh, N., and S. Titman (1993): "Returns to Buying Winners and Selling Losers: Implications for Stock Market Efficiency.," Journal of Finance, 48, 6591.

Jegadeesh, N., and S. Titman (2001): "Profitability of Momentum Strategies: An Evaluation of Alternative Explanations," Journal of Finance, 56, 699-720.

KüNSCH, H. R. (1989): "The jacknife and the bootstrap for general stationary observations," Annals of Statistics, 27, 386-404.

LAKONishoK, J., AND S. SMidt (1984): "Turn-of the year behavior," Journal of Financial Economics, 13, 435-456.

Lewellen, J. (2002): "Momentum and autocorrelation in stock returns," The Review of Financial Studies, 15, 533-563.

Lo, A., AND A. MacKinlay (1990): "Data-snooping biases in tests of financial asset pricing models," Review of Financial Studies, 3, 431-467.

Merton, R. (1987): "On the state of the efficiency market hypothesis in financial economics," in Macroeconomic and Finance: Essays in honor of Franco Modigliani, ed. by R. Dornbush, S. Fisher, and J. Bossons, pp. 93-124. MIT Press.

Moskowitz, T., and M. Grinblatt (1999): "Do industries explain momentum," Journal of Finance, 54, 1249-1290.

Politis, D., And J. Romano (1994): "The stationary bootstrap," Journal of the American Statistical Association, 89, 1303-1313.

Rouwenhorst, G. K. (1998): "International Momentum Strategies," Journal of Finance, 53, 267-284. 
(1999): "Local Return Factors and Turnover in Emerging Stock Markets," Journal of Finance, 54, 1439-1464.

SAVIN, N. E. (1984): "Multiple hypothesis testing," in Handbook of Econometrics, ed. by Z. Griliches, and M. Intriligator, pp. 93-124. North Holland, Amsterdam.

VAn Der Hart, J., E. Slagter, and D. VAn DiJK (2001): "Stock Selection Strategies in Emerging Markets," Tinbergen Institute Discussion Papers, No 01-009/4.

White, H. (2000): "A Reality Check for Data Snooping," Econometrica, 68, $1097-1127$. 


\section{A Appendix}

The stationary bootstrap of Politis and Romano (1994) depends on the specification of $\rho$. When the block length is geometrically distributed, $\rho$ is the inverse of the expected block length. To investigate the robustness of the results in Section 5.1 to the choice of $\rho$, we compute the White's reality check and the nominal pvalues for two additional values of $\rho$ in the bootstrapping procedure i.e. $\rho=0.1$ and $\rho=0.5$. Table A contains the results. By comparing Table A with Table 3 it is seen that $\rho$ do not affect the main conclusions.

Table A.1: Momentum test results, $\rho=0.1$

\begin{tabular}{lcc}
\hline \hline & 17 Industry & Book-to-Market \\
\hline Period & White's p-value & White's p-value \\
\hline $196307-200212$ & $0.002(0.001)$ & $0.116(0.021)$ \\
$196307-198112$ & $0.002(0.001)$ & $0.435(0.037)$ \\
$198201-200212$ & $0.104(0.015)$ & $0.131(0.011)$ \\
\hline \hline & Size & Size-book/market \\
\hline Period & White's p-value & White's p-value \\
\hline $196307-200212$ & $0.005(0.001)$ & $0.021(0.010)$ \\
$196307-198112$ & $0.014(0.002)$ & $0.030(0.019)$ \\
$198201-200212$ & $0.124(0.022)$ & $0.140(0.023)$ \\
\hline \hline
\end{tabular}

Nominal p-value in parenthesis

Table A.2: Momentum test results, $\rho=0.5$

\begin{tabular}{lcc}
\hline \hline & 17 Industry & Book-to-Market \\
\hline Period & White's p-value & White's p-value \\
\hline $196307-200212$ & $0.007(0.001)$ & $0.123(0.021)$ \\
$196307-198112$ & $0.014(0.004)$ & $0.427(0.047)$ \\
$198201-200212$ & $0.148(0.028)$ & $0.146(0.034)$ \\
\hline \hline & Size & Size-book/market \\
\hline Period & White's p-value & White's p-value \\
\hline $196307-200212$ & $0.002(0.001)$ & $0.021(0.017)$ \\
$196307-198112$ & $0.008(0.004)$ & $0.040(0.028)$ \\
$198201-200212$ & $0.159(0.041)$ & $0.170(0.062)$ \\
\hline \hline
\end{tabular}

Nominal p-value in parenthesis 